\title{
An Overview of Performance Enhancement of FHMIPv6 on Wireless Mesh Network
}

\author{
Sashikumar Muthut, Bi-Lynn Ong, Nik Adilah Hanin Zahri, and R. Badlishah Ahmad
}

\begin{abstract}
Currently, there are various Mobile Internet routing Protocols (MIP) available over the mobile Internet network. However, the data of these different types of mobile routing protocols are not sufficient. Moreover, the design of network topology for these mobile routing protocols are least developed. Having known these issues, this research aims to investigate the performance of different types of mobile routing protocol namely, mobile Internet Protocol version 6 (MIPv6), Fast Handover Mobile Internet Protocol version 6 (FMIPv6), Hierarchical Mobile Internet Protocol version 6 (HMIPv6) and Fast Handover with Hierarchical Mobile Internet Protocol version 6 (FHMIPv6) in Wireless Mesh Network (WMN) environment. A topology for all the mobile routing protocols is proposed to be designed and developed. At the end of this research, it is believe that the design and develop FHMIPv6 over WMN performs better as compare to the others routing protocols over the Internet.
\end{abstract}

Index Terms-FMIPv6, HMIPv6, FHMIPv6, WMN.

\section{INTRODUCTION}

The technology of wireless communication is increasingly utilized by the Internet users. Gradually, more and more users connect wireless devices to the Internet. These cause lots of congestion and disconnection because of the huge number of users. Therefore, lots of researches have been conducted to solve the congestion and disconnection issues over the wireless communication. Fast Handover Mobile Internet Protocol version 6 (FMIPv6) as in Fig. 1 and Hierarchical Mobile Internet Protocol version 6 (HMIPv6) as in Fig. 2 are both Mobile Internet Protocol introduced to solve the congestion and disconnection issues. Both FMIPv6 and HMIPv6 had been designed to improve the handoff duration for mobile connection. HMIPv6 is designed to reduce the amount of signaling and FMIPv6 is designed to reduce the service degradation by minimizing the time during which a mobile node is unable to send or receive IP packets. Both the FHMIPv6 and HMIPv6 need further improvement to enhance the mobility management for the wireless users.

FHMIPv6 is a protocol that combines Hierarchical MIPv6 (HMIPv6) and Fast handover for MIPv6 (FMIPv6) extensions to MIPv6. Fast Handover for Hierarchical Mobile IPv6 reduces delay during handover by using HMIPv6 procedures. Hence, researchers have introduced new research field in wireless mesh networks (WMN) which less research is

Manuscript received December 15, 2014; revised March 6, 2015.

The authors are with Computer and Communication Engineering Department, Universiti Malaysia Perlis (UniMAP), Malaysia (e-mail: sashikumar88@yahoo.com, adilahhanin@unimap.edu.my, badli@unimap.edu.my). being performed thoroughly, although a significant amount of research on wireless and cellular network mobility management have been addressed. Figures below represent mobility management in IPv6.

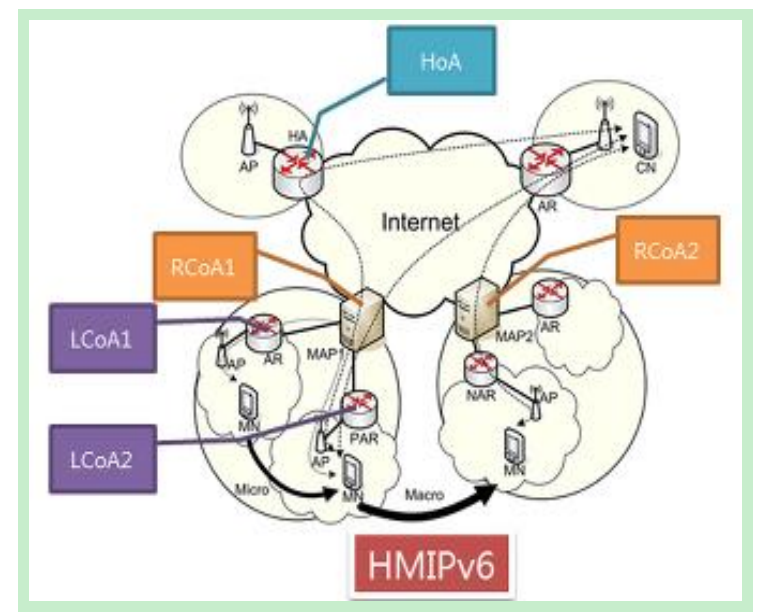

Fig. 1. Network diagram of FMIPv6.

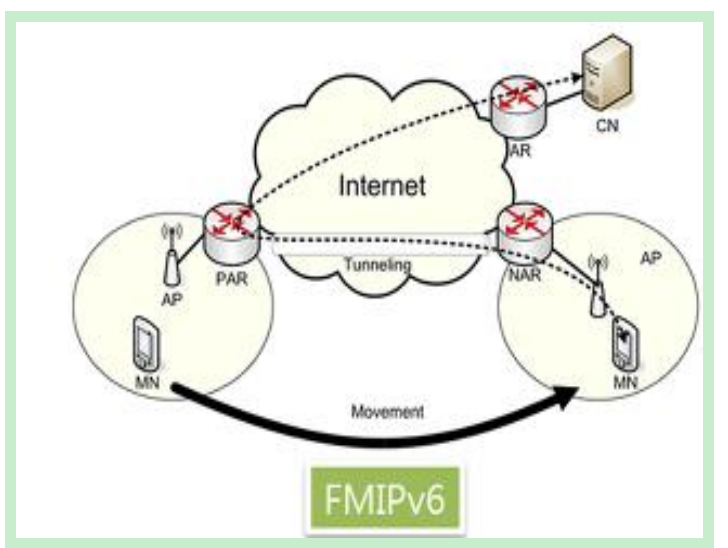

Fig. 2. Network diagram of HMIPv6.

WMN can be connected to wireless networks such as worldwide interoperability microwave access (WiMAX), generic wireless fidelity (Wi-Fi); cellular and sensor networks. Third and Fourth Generation (4G) networks includes all Internet Protocol (IP) which is wired and wireless networks interworks together as heterogeneous networks [1]. However, the challenge is to connect to MIPv6-based mobility management. MIPv6 and its extensions rely on the good performance of an infrastructure-based network but a typical WMN topology tends to be an unplanned graph and routes of it changes dynamically [2], [3]. Mobility management provides an undisrupted support of real-time and non-real-time services for mobile network users and facilitates the maintenance of connections for users on the move when they change their points of attachment from 1 access point (AP) to another. Mobility management involves 
handover management and location management. Handover management is a procedure that allows mobile node to keep its connection undisrupted when it moves from one point to another. Location management allows the system to keep track of the location of a mobile node [2]. Handover can be categorized in to 2, which are vertical and horizontal handovers. Vertical handover refers to the ability to roam between heterogeneous wireless networks. Horizontal handover refers to the move from one access point to the other within the same network subnet. Having discussed the location management and mobility management over the networks, in this research, Mobile Internet Protocols (MIPv6, FHMIPv6, HMIPv6 and FHMIPv6 on WMN) are studied firmly in terms of performance matrix: delay/latency, throughput and packet loss. The Wireless Mesh Network (WMN) topology is developed by using network simulation software and the result obtained are analyzed.

\section{RELATED WORKS}

Zimani Chitedze and William D. Tucker et al. [2] had investigated FHMIPv6-based Handover for Wireless Mesh Networks (WMNs). The authors have compared four types of mobile routing protocol to identify the best routing protocol for mobile network, that are Mobile Internet Protocol version 6 (MIPv6), Fast Handover Mobile Internet Protocol version 6 (FMIPv6), Hierarchical Mobile Internet Protocol version 6 (HMIPv6) and Fast Handover for Hierarchical Internet Protocol version 6 (FHMIPv6). Network Simulator (Ns 2.32) version 2.32 has been used to conduct the simulation. The authors have taken in count the performance matrix of throughput, average delay, and packet loss. The overall simulation results shows that Fast Handover for Hierarchical Internet protocol version 6 (FHMIPv6) performed extremely well compared to other protocol in Wireless Mesh Network (WMN).

Shaojian Fu, Mohammed Atiquzzaman et al. [4] had investigated handover latency comparison of SIGMA, FMIPv6, HMIPv6, and FHMIPv6. The researches had designed a new scheme for supporting low latency; low packet loss mobility called Seamless IP diversity based Generalized Mobility Architecture (SIGMA). They had compared the handover latency of SIGMA with, FMIPv6, HMIPv6, and FHMIPv6. The researches have taken in count various parameters such as layer 2 handover/setup latency, IP address resolution latency, layer 2 beacon period, and mobile host moving speed. The researches had used Network Simulator version 2 (NS-2) to run the simulation. They concluded that, the handover latency of SIGMA is lower than that of MIPv6 enhancements under various simulated scenarios. SIGMA could also seamlessly handle relatively high speed movement.

Xavier Pérez-Costa, Marc Torrent-Moreno and Hannes Hartenstein et al. [5] had investigated A Performance Comparison of Mobile IPv6, Hierarchical Mobile IPv6; Fast Handovers for Mobile IPv6 and their Combination. The researches had done simulation using the (NS-2) Network Simulator version 2 software. The simulation scenario comprises four access routers and up to 50 mobile nodes. The performance matrixes the researches have taken in count are handoff latency, packet loss rate, achieved bandwidth per station and signaling load. The authors concluded that, both the FMIPv6 and the combined version FHMIPv6 performed well during the simulation testing with low on packet losses, lesser latency and also fair amount of bandwidth achieved.

Michal Skořepa, Richard Klügl et al. [6] had investigated Analytical comparison of Mobile IPv6 handover schemes. The authors had done comparison for four most common handover schemes in term of the cost of packet delivery of Mobile IPv6 that is MIPv6, FMIPv6, HMIPv6 and FHMIPv6. They used analytical methods for the comparison. The researchers used network simulation software to run the simulation. The researchers have taken in count these two performance matrix during the comparison that is, the handover cost and handover latency. The authors concluded the hierarchical internet protocol consists of HMIPv6 and FHMIPv6 performed well compared to other internet protocol in terms of packet delivery cost.

Anne Wei, GouZhi Wei and Benoit Gellerzx et al. [7] had investigated Improving Mobile IPv6 Handover in Wireless Network with E-HCF. In this research, the researchers have introduced a new control function called Extended Handover Control Function (E-HCF) in order to improve the handover performance over the wireless network. For research and analysis purpose the researches have used OPNET network simulation software to run the simulation. The performance matrix that was taken in count was the handover latency and packet loss. The authors' aims are to reduce the end-to-end delay and packet loss by implementing the new function called Extended Handover Control Function $(E-H C F)$. At the end of the research, the researchers concluded the $E-H C F$ approach enables to decrease both the total handover latency and the packet loss significantly.

\section{TERMINOLOGY}

\section{A. $M I P v 6$}

Internet Engineering Task Force (IEFT) brought into use of Mobile Internet Protocol version 6 (MIPv6) to allow mobile nodes $(\mathrm{MN})$ to be reachable and maintained on-going connection while changing location within topology without changing the allocated IP address [8]. The operation of MIPv6 is as illustrated in Fig. 3 and Fig. 4. The operation begins as MN detects movement to a Foreign Agent (FA) and auto configures itself with a New Care of Address (NCoA) using either stateful or stateless method. MN sends Binding Update (BU) to its Home Agent (HA) to notify the new address and HA returns back Binding Acknowledgment (BAck). Then, all packets is tunneled to MN's NCoA with the help of HA as HA encapsulate packets and sends to MN's $\mathrm{NCoA}$ and $\mathrm{MN}$ decapsulate the packets received from HA. An additional mode for MIPv6 is Route Optimization (RO). It allows the packets to be delivered using shortest path. This process requires $\mathrm{MN}$ to register its current Binding to Corresponding Node $(\mathrm{CN})$. This allows $\mathrm{CN}$ to triangulate packets to be delivered to MN without concerning HA. This measure reduces congestion at MN's HA and Home Link.

\section{B. $H M I P v 6$}

Hierarchical Mobile Internet Protocol version 6 (HMIPv6) 
is the improved version of Mobile Internet Protocol version 6 (MIPv6) that has a new technology incorporated in it which is Mobility Anchor Point (MAP). Reason behind the introduction of this technology is to decrease the handover latency and to reduce the amount of signaling between the Mobile Node (MN), Correspondent Nodes (CN), and Home Agent (HA) [9]. Process flow of HMIPv6 is shown in Fig. 5. Operation of HMIPv6 involves in three phases that are 1) MAP Discovery, 2) MAP Registration and 3) Packet Forwarding. The MAP discovery procedure is the first step in attaining a successful connection [10]. The MAP is a router located in a network visited by the MN. The discovery begins as soon as the visit point router starts to advertise. There are two discovery options that are Static Configuration and Dynamic MAP Discovery. After the visiting MN process through the discovery options, the MN obtains its MAP IP address and then it calculates the distance of MAP from the current Access Router (AR). It also verifies the connection strength between the AR and the MAP. Second step is MAP registration that is to register the MN to the MAP. The visit point router assigned as Regional Care-of-Address (RCoA). The RCoA is an address obtained by the MN from the visited network. The RCoA is formed using the prefix advertised by the visit point router. The $\mathrm{MN}$ assigns as On Link Care-of-Address (LCoA). LCoA is configured on a MN's interface based on the prefix advertised by its default router (AR). Next, the MN creates a binding between the RCoA and LCoA at the MAP. Then, MN sends Local Biding Update (LBU) to the newly discovered MAP. Next, the HA performs Duplicate Address Detection (DAD) and updates the binding cache. Then, MAP sends a Binding Acknowledgement (BAck) to $\mathrm{MN}$. After this process, MN sends binding update to its HA and active CN's with RCoA as its source address and HA, CN's address as destination address. The last step is to forward packets which are performed after the discovery and registration process. $\mathrm{A} \mathrm{Bi}$ - directional tunnel between the MAP and the MN is established. All packets sent by the MN are tunneled to the MAP and also all packets destined to the MN's RCoA are intercepted by the MAP and tunneled to the MN's LCoA.

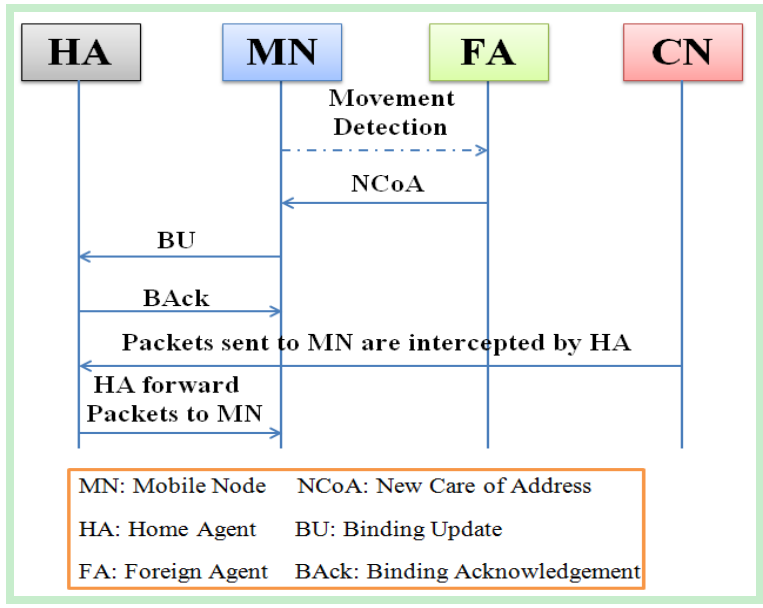

Fig. 3. MIPv6 flow diagram.

\section{FMIPv6}

Fast Handover Mobile Internet Protocol version 6 (FMIPv6) is the improved version of Mobile Internet
Protocol version 6 (MIPv6). FMIPv6 contains three FMIPv6 signaling messages which involved in the anticipation phase that are Router Solicitation for Proxy Advertisement (RtSolPr), Proxy Router Advertisement (PrRtAdv) and Fast Binding Update (FBU) [12]. These signaling methods were introduced to minimize the packet losses and latency due to the handoff process. The Fast Handover for Mobile Internet Protocol version 6 (FMIPv6) is divided into two types that are Predictive Fast Handover and Reactive Fast Handover.

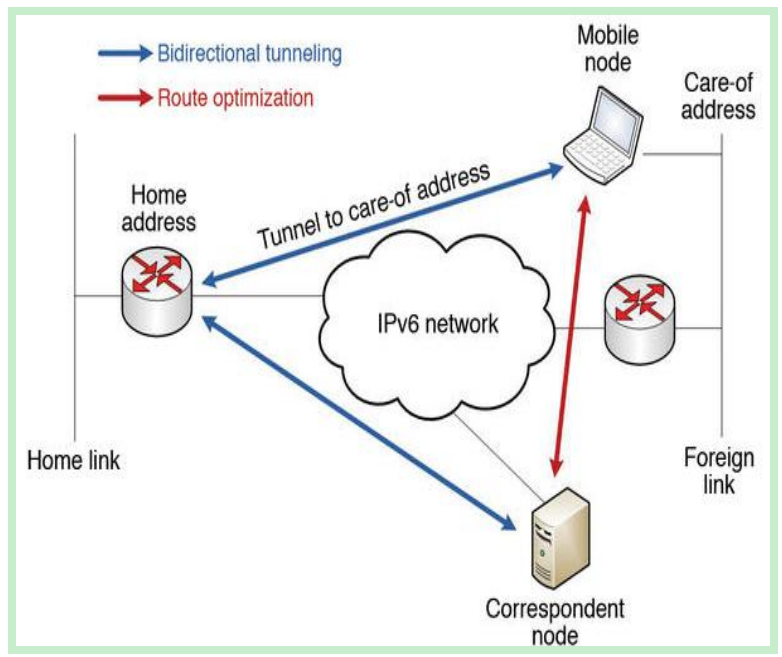

Fig. 4. MIPv6 network diagram.

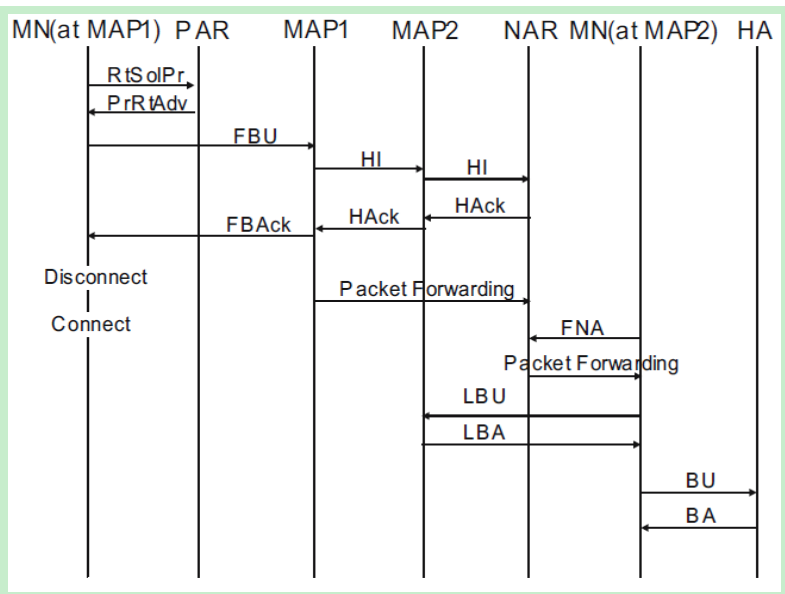

Fig. 5. HMIPv6 flow diagram [11].

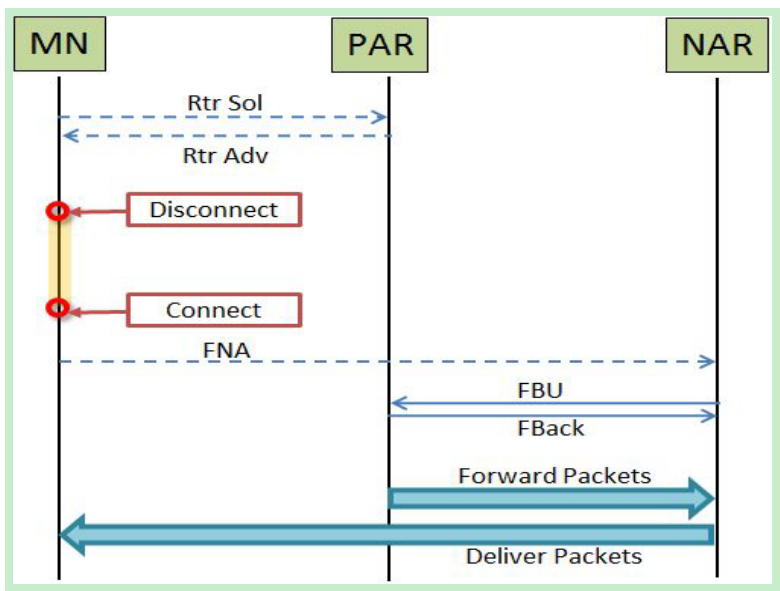

Fig. 6. Reactive protocol flow diagram.

Predictive Fast Handover as illustrated in Fig. 6, allows the Mobile node (MN) to send fast Binding Update (FBU) even before it is attached to the New Access Router (NAR) [13]. 
Reactive Fast Handover as shown in Fig. 7, only allows MN to send FBU after it is attached to the NAR. However both the protocols involved in the same 3 operation stages which are handover initiation, tunnel establishment and packet forwarding. Process begins right after MN sends out RtSolPr to PAR requesting for a potential handover. PAR scans through the network subnet and returns back a PrRtAdv message containing the possible Access Points (APs) id or Access Routers (ARs) id to MN.

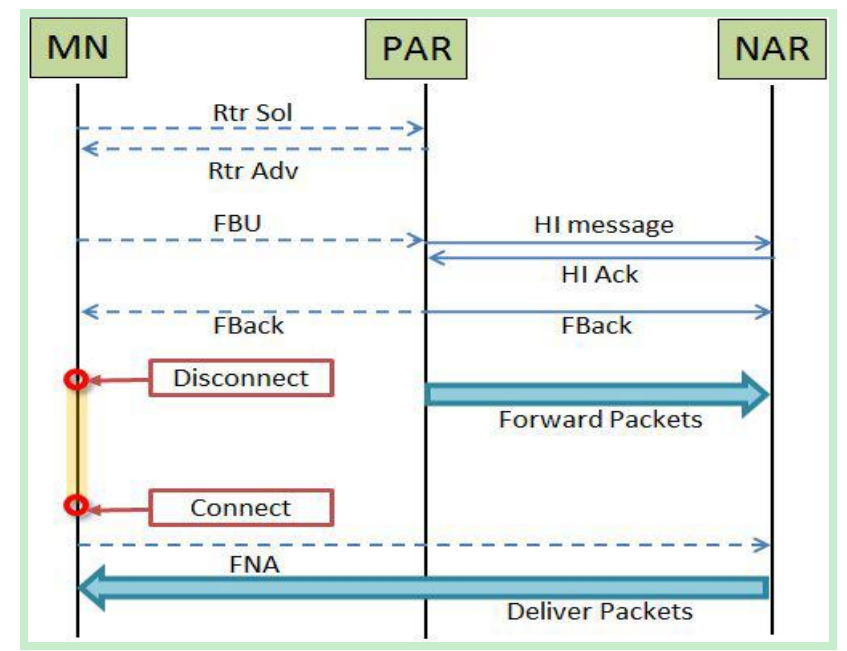

Fig. 7. Predictive protocol flow diagram.

Next, MN sends Fast Binding Update (FBU) to the PAR requesting PAR to send a handover initiate $(\mathrm{HI})$ to the NAR to obtain New Care of Address (NCoA) so that all the packets arriving to the Previous Care Of Address (PCoA) can be tunneled to the NCoA. NAR performs Duplicate Address Detection (DAD) and returns Handover Acknowledgement (Hack) to the PAR with the tunnel establishment. Next, PAR sends Binding Acknowledgements (Back) to MN and NAR. In the last step, the MN sends a Fast Neighbor Advertisement (FNA) to the NAR. This is to inform that the MN is in the NAR subnet and the NAR returns the FNA-ACK to the MN.

\section{FHMIPv6 in Wireless Mesh Network}

Fast Hierarchical Mobile Internet Protocol version 6 (FHMIPv6) in Wireless Mesh Network (WMN) comprises in two parts that are, Inter network and Intra network as presented in Fig. 8. The inter network section is FHMIPv6 process and the Intra network part is the WMN process. This study combines both the technologies and produces an enhanced Mobile Internet Protocol (MIP), the process flow is shown in Fig. 9. FHMIPv6 proposed by Robert Hsieh, Aruna Seneviratne, Hesham Soliman and Karim El-Malki et al. [14] is the combination of Fast Handover Mobile Internet (FMIP) and Hierarchical Mobile Internet Protocol (HMIP). This combination combines advantages from both the Internet Protocol (FMIP \& HMIP) that generates lower packet losses, lower handover delays and better throughput [15]. The FHMIPv6 operation begins with L2 handover anticipation where the MN sends RtSolPr message containing information of NAR to MAP. Next, MAP sends out PrRtAdv message to the $\mathrm{MN}$, which contains information of New Link Care of Address (NLCoA) for MN to use in NAR region. Then, the MN sends out Fast Binding Update (FBU) to MAP, which encloses Previous Link Care Of Address (PLCoA) and IP address of the NAR.

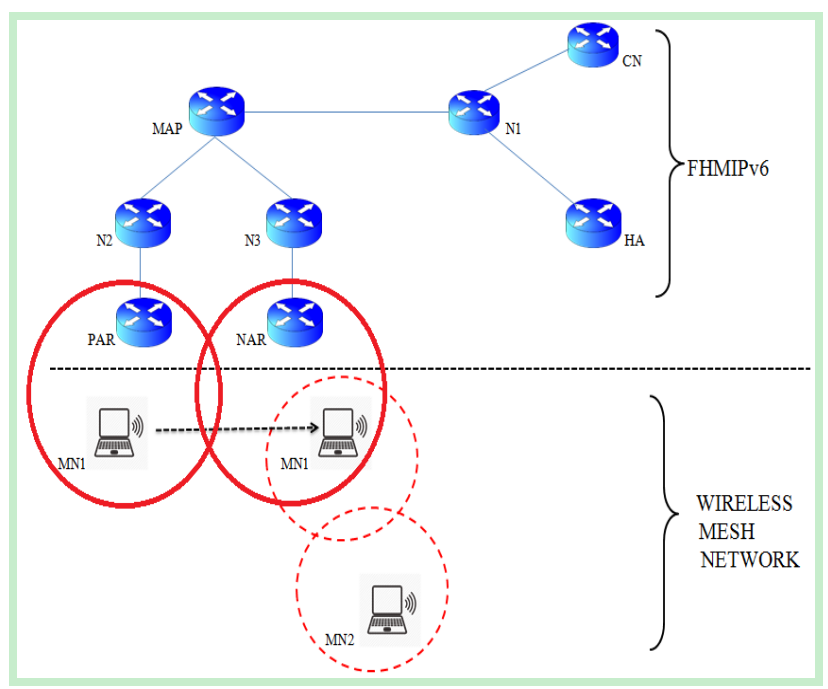

Fig. 8. FHMIPv6 in WMN network diagram.

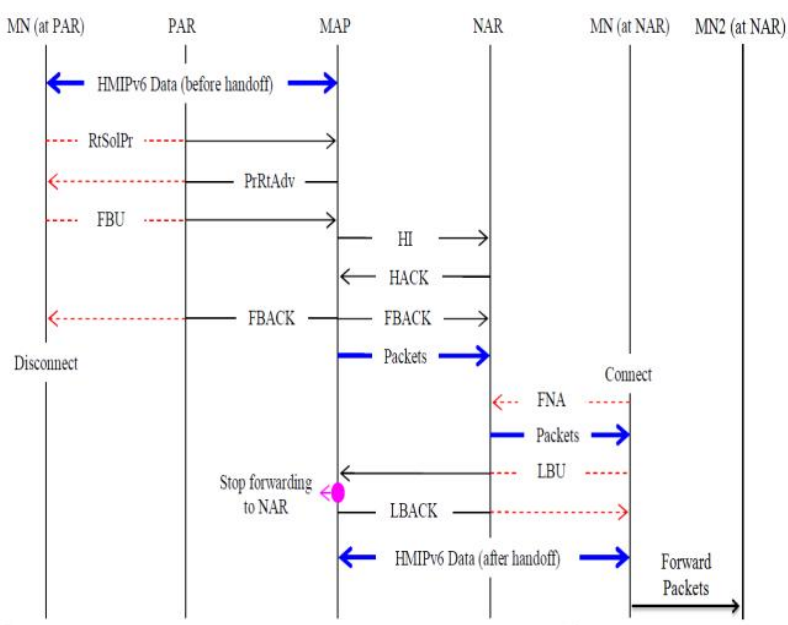

Fig. 9. FHMIPv6 in WMN flow diagram.

Once MAP received FBU from MN, MAP sends out Handover Initiate (HI) to NAR. In response to the HI message, NAR sets up a host route for the MN's PLCoA and responds with a Handover Acknowledge (HACK) message. A bi-directional tunnel between MAP and NAR is established. After that, MAP sends out Fast Binding Acknowledgement (FBACK) toward MN over PAR and NAR. Then, MAP begins to forward data packets destined to MN to the NAR by using the established tunnel. Once the MN is in NAR, it sends out Fast Neighbor Advertisement (FNA) to the NAR and NAR returns the FNA-ACK to the MN. Then, MN sends Local Biding Update (LBU) to MAP. Next, the HA performs Duplicate Address Detection (DAD) and updates the binding cache. Then, MAP sends a Binding Acknowledgement (BAck) to $\mathrm{MN}$. After this process, $\mathrm{MN}$ sends binding update to it's HA and active CN's with NLCoA as its source address and HA, CN's address as destination address. Next, inter network handover begins, that is allowing the data to flow through without having MN2 be in the radius of New Access Router (NAR). MN1 is able to reconfigure itself to be a mesh router and MN2 connects to MN1 as mesh client to be able to communicate with each other as a mesh network. By implementing this hybrid internetwork connection, the data can reach the designated destination in less time compared to conventional wireless network method [16]. 


\section{CONCLUSION}

In this research, MIPv6, FMIPv6, HMIPv6, FHMIPv6 and FHMIPv6 over the WMN have been discussed in details in this paper. The aim of the design FHMIPv6 over WMN is to reduce the delay in wireless communication. Additionally, it aims to increase the throughput. Having decreased the delay and increased the throughput, these can provide better service quality to the wireless Internet users. Thus, we believe that having developed this proposed protocol, this enhanced protocol is able to improve the service quality of wireless communication.

\section{REFERENCES}

[1] S. Hui and K. Yeung, "Challenges in the migration to $4 \mathrm{G}$ mobile systems," Commun. Mag. IEEE, December, pp. 54-59, 2003.

[2] Z. Chitedze and W. Tucker, "FHMIPv6-based handover for wireless mesh networks," in Proc. South. Africa Telecommun. Networks Appl. Conf., 2012, pp. 1-5.

[3] I. Akyildiz and X. Wang, "A survey on wireless mesh networks," Commun. Mag. IEEE, September, pp. 23-30, 2005.

[4] S. Fu and M. Atiquzzaman, "Handover latency comparison of SIGMA, FMIPv6, HMIPv6, FHMIPv6," in Proc. Global Telecommunications Conference, no. C, 2005.

[5] X. Pérez-Costa, M. Torrent-Moreno, and H. Hartenstein, "A performance comparison of Mobile IPv6, Hierarchical Mobile IPv6, fast handovers for Mobile IPv6 and their combination," $A C M$ SIGMOBILE Mob. Comput. Commun. Rev., vol. 7, no. 4, p. 5, Oct. 2003.

[6] M. Sko and R. Klügl, Analytical Comparison of Mobile IPv6 Handover Schemes, vol. 2, no. 2, pp. 22-26, 2011.

[7] A. Wei, G. Wei, and B. Geller, "Improving mobile IPv6 handover in wireless network with E-HCF," in Proc. 2008 IEEE 68th Veh. Technol. Conf., Sep. 2008, pp. 1-5.

[8] S. Sinan, M. Ismail, and K. Jumari, "A comparison of mobile node's handoff between mobile IPv6 and fast handover protocol," J. - Inst. Eng. Malaysia, vol. 69, no. 2, pp. 27-30, 2008.

[9] A. Yadav and A. Singh, "Performance analysis and optimization of Hmipv6 And Fmipv6 handoff management protocols," Int. J. Eng. Res., vol. 5013, no. 3, pp. 305-308, 2014.

[10] Y. Zhang and H. Bi, "The simulation of hierarchical mobile IPv6 with fast handover using NS2," Procedia Eng., vol. 37, pp. 214-217, Jan. 2012.

[11] G. Koo, K. Yu, M. Noh, and Y. Mun, "Improved fast handover protocol using HMIPv6 based on IEEE 802.16 e network," Computational Science and Its Applications, pp. 415-423, 2007.

[12] J. Ortiz and J. Perea, "Integration of protocols FHMIPv6/MPLS in hybrid networks," Cyber Journals: Multidisciplinary Journals in Science and Technology, Journal of Selected Areas in Telecommunications (JSAT), 2011.

[13] B. Liu, P. Martins, and P. Bertin, "The operation mode selection in FMIPv6," presented at IEEE Symposium on Computers and Communications, 2008.

[14] R. Hsieh, A. Seneviratne, H. Soliman, and K. El-malki, "Performance analysis on Hierarchical Mobile IPv6 with," in Proc. Glob. Telecommun. Conf., vol. 3, pp. 2488-2492, 2002.

[15] B. Yew, B. Ong, and R. Ahmad, "Performance evaluation of TCP variants in hierarchical mobile IPv6 network with fast-handover
(FHMIPv6) on network simulator 2 (ns2)," in Proc. Int. Conf. Man Mach. Syst. 2012, vol. 2, 2012.

[16] M. L. Sanni, A.-H. A. Hashim, W. Haslina Hassan, F. Anwar, A. W. Naji, and G. S. M. Ahmed, "Architectural framework for mobile multicast support in wireless mesh networks," Science Asia, vol. 39S, no. 1 , p. 95,2013 .

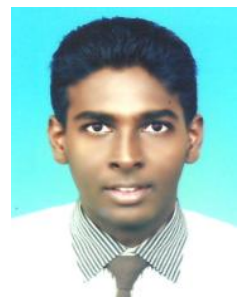

Sashikumar Muthut graduated with the B.Eng (Hons) in computer network engineering from Universiti Malaysia Perlis (UniMAP) in the year 2013. He received his diploma in electronics engineering from Sultan Haji Ahmad Shah Polytechnic (POLISAS) Kuantan in the year 2009. Currently, he is presuming his postgraduate master research at Universiti Malaysia Perlis (UniMAP) in the field of computer engineering majoring in computer networking. His research interests are in the field of mobility management, handover management and Internet Protocol (IP).

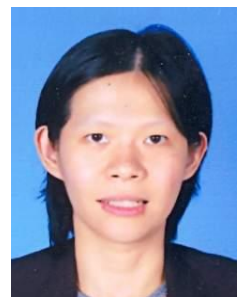

Ong Bi Lynn graduated with the B.Eng. (Hons) in electrical and electronics from Universiti Malaysia Sabah (UMS) in the year 2001. She received her master of business administration from Universiti Utara Malaysia (UUM) in 2003. She obtained her $\mathrm{Ph} . \mathrm{D}$. in the field of computer network in the year 2008 from Universiti Utara Malaysia (UUM). Currently, she is working with the Department of Computer Network Engineering, School of Computer and Communication Engineering in Universiti Malaysia Perlis (UniMAP), Perlis, Malaysia.

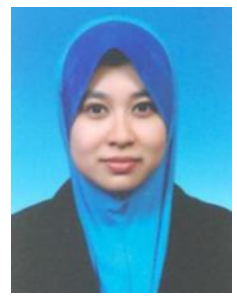

Nik Adilah Hanin Zahri graduated from computer science and media engineering, University of Yamanashi in 2006. She received the M.Sc in 2009 and the Ph.D. in human environmental medical engineering in 2013 from Interdisciplinary Graduate School of Medicine and Engineering, University of Yamanashi, Japan. Currently, she is working at the Department of Computer Engineering, School of Computer and Communication Engineering in University of Malaysia Perlis (UniMAP), Malaysia.

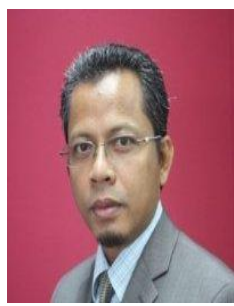

R. Badlishah Ahmad obtained the bachelor of engineering with honors (B.Eng. (Hons)) in electrical \& electronic engineering from Glasgow University in 1994. He continued his master of sciences (M.Sc.) in optical electronic engineering at University of Strathclyde and graduated in 1995 . He then continued his study at Ph.D level at the same university and completed in 2000. His research interests are in computer and telecommunication network modeling, optical networking and embedded system based on GNU/Linux. He has four years teaching and research experiences in Universiti Sains Malaysia (USM). Since 2004 until now he is working in Universiti Malaysia Perlis (UniMAP). $\mathrm{He}$ is currently the dean and a professor at the School of Computer and Communication Engineering and also the head of Embedded Computing Research Cluster, Universiti Malaysia Perlis (UniMAP). He has developed 3 undergraduate and 1 M.Sc. (Mix mode) programs. He has authored and coauthored more than 300 conferences and journal papers. He has supervised more than 20 Master of Science (Research) students and 14 Ph.D. students. He is currently supervising $10 \mathrm{Ph} . \mathrm{D}$ students in his research area. 